Chapter 35.

\title{
Potato Production in Florida
}

C.M. Hutchinson, E.H. Simonne, G.J. Hochmuth, D.N. Maynard, W.M. Stall, S.M. Olson, S.E. Webb, T.G. Taylor, S.A. Smith

\author{
BOTANY \\ Family - Solanaceae \\ Potato - Solanum tuberosum L. \\ Origin \\ The potato is native to the Andean highlands of Peru.

\section{Related Species} \\ Tomato, pepper, and eggplant are other important veg- \\ etables in the Solanaceae family. Tomatillo and pepino, \\ of much less economic importance in Florida, are also \\ in this family. In addition, many plants in this family are \\ used as ornamentals. Some, like tobacco, contain powerful \\ alkaloids which may be addictive, poisonous, or useful as \\ pharmaceuticals.
}

\section{VARIETIES}

Variety selection, often made several months before planting, is one of the most important management decisions made by the grower. Failure to select the most suitable variety or varieties may lead to loss of yield or market acceptability.

The following characteristics should be considered in selection of potato varieties for use in Florida:

Yield - The selected should have the potential to produce crops at least equivalent to the current market standards. The typical yield for Florida fresh market varieties ranges from $225-350 \mathrm{cwt} / \mathrm{acre}$. Production falls on the lower end of the scale in the southern counties and increases as production moves into northern counties.

A typical yield for chip potato production is $275-400$ cwt/acre. Chip potato production areas are located from mid-state counties on both coasts to northern counties.

Disease, Insect, and Nematode Tolerance - Varieties having disease, insect, and nematode tolerance should be selected when all other factors are equal.
Horticultural Quality - Earliness is an important characteristic for Florida production as the average season length is 100 days. Other important qualities, depending on variety usage, include appropriate skin type, set, and color; taste and mouth feel; uniform tuber shape and size; shallow eyes; and relative specific gravity should all be considered.

Adaptability - Potatoes in Florida are grown as day length increases and temperature change from cool to warm. This is opposite compared to many other production areas in the world. New varieties should be tested on limited acreage and accepted by the public and/or processor before planting on wider acreage. All popular northern varieties do not produce well in Florida because of Florida growing conditions.

Market Acceptance - New varieties must have characteristics that are appreciated by consumers. In addition, many other entities in the production chain such as packer, processor, and/or retailer all have demands that the variety must meet.

\section{POTATO VARIETIES FOR COMMERCIAL PRODUCTION}

\section{Chipping Varieties}

ATLANTIC - With high yield potential, high specific gravity and uniform tuber size and shape, Atlantic is the standard variety for chipping from the field or from very short-term storage. The cultivar is tolerant to scab and Verticillium wilt; resistant to pinkeye; and highly resistant to Race A of golden nematode, virus X and tuber net necrosis. Tubers are susceptible to internal heat necrosis, particularly in sandy soils in warm, dry seasons. Hollow heart in the larger diameter tubers ( $>3$ in) can be serious in some growing areas when growing conditions over the season fluctuate

HARLEY BLACKWELL -Harley Blackwell is a round, white-, netted-skinned cultivar, resistant to internal heat necrosis, for chipping directly from the field in the mid-Atlantic states. Harley Blackwell is resistant to race a of golden nematode, air pollution susceptible, Verticillium 
wilt, late blight. It is moderately susceptible to early blight with intermediate resistance to common scab and some tolerance to powdery scab.

\section{Fresh Market/Table Varieties}

RED LASODA - Red LaSoda is an early to medium season, red-skinned variety that is primarily grown in the southeastern U.S. It is harvested in the winter months as a fresh market variety. Red LaSoda has a high yield potential of tubers with a bright red color. Tubers size early. Tuber eye depth and off-shape tubers are limitations. The cultivar is susceptible to early and late blights, scab, corky ringspot, and bacterial wilt. Red LaSoda is the top planted red-skinned potato variety in Florida.

LAROUGE - LaRouge is a early to medium maturing, red-skinned variety that has a high tuber yield potential with tubers sizing early. Primary growing areas are in the southeastern U.S. The variety is grown for the fresh market and is generally not stored. LaRouge has good scab resistance but is susceptible to early and late blights, corky ringspot, and bacterial wilt. The deep eyes and irregular tuber shape are the major limitations. When harvested in southern states the relatively high yield, bright color, and good boiling qualities make it popular for markets in the late winter.

LACHIPPER - LaChipper is an early to midseason variety with moderate to high tuber yield and moderate specific gravity. It is the top planted fresh market whiteskinned variety in Florida. Tubers are more elongated than round, somewhat flattened. Skin is smooth and white with medium to deep, cream colored eyes that are fairly evenly distributed. Tuber flesh is very white. La Chipper possesses some resistance to late blight. It is moderately susceptible to common scab. Exposure to air pollution can result in defoliation and reduction in tuber yield. Deep eyes and irregular shape are disadvantages on the tablestock market.

SEBAGO - Sebago was released by the USDA and the Maine Agricultural Experiment Station in 1938. Tubers are elliptical to round with a smooth, ivory skin. Specific gravity is medium to low. Sebago is recognized statewide as having excellent flavor but it lacks some important horticultural qualities to compete equally with current fresh market standards. When grown in the south, the variety's maturity is considered medium. Tubers grown under ideal conditions are attractive but are susceptible to prominent lenticels under wet conditions. Sebago is resistant to net necrosis and wart and has moderate resistance to early and late blight, southern bacterial wilt, PVX, PVY, PVA and some resistance to scab. The variety is highly susceptible to blackleg.

YUKON GOLD - Yukon Gold has early-medium maturity, moderate yields, moderate specific gravity and relatively attractive tuber type. Tubers slightly oval, may be somewhat flattened with yellow-white skin and light yellow tuber flesh. Its shallow, pink eyes distinguish Yukon Gold from other yellow-skinned, yellow-fleshed cultivars. Yukon Gold is resistant to mild mosaic, moderately resistant to leafroll virus and susceptible to virus $\mathrm{Y}$, common scab and air pollution. In some growing areas, hollow heart and internal heat necrosis may be a problem. Yukon Gold retains the yellow flesh color when baked, boiled or french-fried.

GOLDRUSH - Goldrush is a medium maturing russet cultivar grown primarily for the fresh market. Russetskinned tubers are oblong to long and average approximately 6-10 tubers per plant. Eyes are very shallow and well distributed; under some conditions they may show a reddish blush. Tuber flesh is very white and tuber dormancy is medium in duration. Goldrush has been observed to have moderate resistance to Verticillium wilt, good resistance to scab, moderate resistance to blackspot and some resistance to silver scurf. It is considered susceptible to most common potato viruses and other potato diseases, such as early blight, late blight, soft rot and Fusarium dry rot.

GENERAL INFORMATION - Production, quality, and disease resistance information is not provided for proprietary varieties. Information on proprietary varieties can be obtained by private or licensing company.

For further information on potato varieties for Florida production refer to the following EDIS documents:

Fresh market red and purple-skinned potato varieties for commercial production in northeast Florida. http://edis.ifas. $\underline{\text { ufl.edu/CV283 }}$

Fresh market white-skinned potato varieties for commercial production in northeast Florida. http://edis.ifas.ufl. edu/CV282

Fresh market russet potato varieties for commercial production in northeast Florida. http://edis.ifas.ufl.edu/CV281

Chip potato varieties for commercial production in northeast Florida. http://edis.ifas.ufl.edu/CV280

Potato vine killing or desiccation. http://edis.ifas.ufl. $\underline{\text { edu/HS181 }}$

Growing potatoes in the Florida home garden. http:// edis.ifas.ufl.edu/HS183

Potato physiological disorders - growth cracks. http:// edis.ifas.ufl.edu/HS182

Potato physiological disorders - brown center and hollow heart. http://edis.ifas.ufl.edu/HS197 


\section{SEEDING AND PLANTING}

Planting date and seeding information are given in Table 1.

Table1. General potato planting information.

\begin{tabular}{|lc||}
\hline \multicolumn{2}{|c|}{ Planting dates } \\
\hline \hline North Florida & Jan-Feb \\
Central Florida & Dec-Feb \\
South Florida $\quad$ Planting information & Oct-Jan ${ }^{1}$ \\
& \\
\hline \hline & \multicolumn{2}{|c|}{ Distance between rows (inch) } & $36-42$ \\
Distance between plants (inch) & $5-10$ \\
Planting depth (inch) & $3-4$ \\
Average seed piece size (oz) & $2.5-3.0$ \\
Average seed per planted acre (Ib) & $2000-3000$ \\
Days from planting to tuber maturity & $85-110$. \\
\hline
\end{tabular}

\section{FERTILIZER AND LIME}

For subsurface or sprinkler irrigated crops, band all $\mathrm{P}_{2} \mathrm{O}_{5}$, micronutrients, $\mathrm{K}_{2} \mathrm{O}(50 \%)$, and nitrogen (50\%) in bed at planting. When plants reach a 10-12 inch growth stage (approximately 35-40 days after planting), band or
Table 2. Planting information for potato.

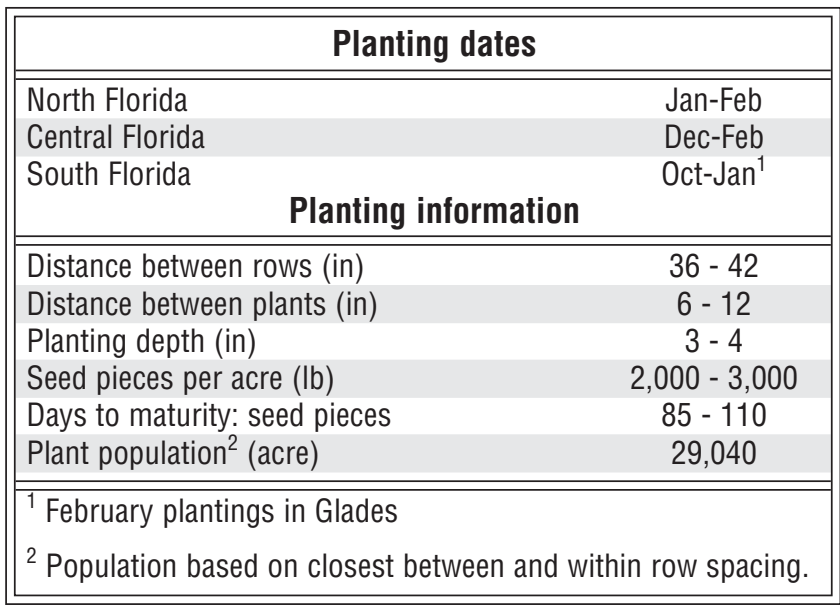

Table 3. Soil test and fertilizer recommendations for mineral soils for potato (based on 40 to 42 inch centers). ${ }^{1}$

\begin{tabular}{|c|c|c|c|c|c|c|c|}
\hline \multirow[t]{2}{*}{ Target pH } & \multirow[t]{2}{*}{$N(\mathrm{Ib} / \mathrm{A})$} & \multirow[t]{2}{*}{$\mathrm{K}_{2} \mathrm{O}(\mathrm{Ib} / \mathrm{A})$} & VL & $\mathbf{L}$ & M & $\mathrm{H}$ & VH \\
\hline & & & \multicolumn{5}{|c|}{$\begin{array}{c}\mathrm{P}_{2} \mathrm{O}_{5} \\
\text { (Ib/A/crop season) }\end{array}$} \\
\hline 6.0 & 200 & 150 & 120 & 120 & 60 & 0 & 0 \\
\hline
\end{tabular}

Table 4. Plant tissue analysis for potato plants 10 inches tall. Dry wt. basis.

\begin{tabular}{|c|c|c|c|c|c|c|c|c|c|c|c|c|}
\hline \multirow[b]{2}{*}{ Status } & $\mathbf{N}$ & $\mathbf{P}$ & K & $\mathrm{Ca}$ & $\mathrm{Mg}$ & $S$ & $\mathrm{Fe}$ & Mn & $\mathrm{Zn}$ & B & $\mathrm{Cu}$ & Mo \\
\hline & \multicolumn{6}{|c|}{ Percent } & \multicolumn{6}{|c|}{ Parts per million } \\
\hline Deficient & $<3.0$ & 0.2 & 3.5 & 0.6 & 0.3 & 0.25 & 40 & 30 & 30 & 20 & 5 & 0.1 \\
\hline Adequate range & $3.0-6.0$ & $0.2-0.8$ & $3.5-6.0$ & $0.6-2.0$ & $0.3-0.6$ & $0.25-0.50$ & $40-150$ & $30-60$ & $30-60$ & $20-60$ & $5-10$ & $0.1-0.2$ \\
\hline High & $>6.0$ & 0.8 & 6.0 & 2.0 & 0.6 & 0.50 & 150 & 60 & 60 & 60 & 10 & 0.5 \\
\hline
\end{tabular}

Table 5. Sufficiency ranges for petiole sap testing for potato.

\begin{tabular}{|lcc|}
\hline Crop development stage & \multicolumn{2}{c|}{ Fresh petiole sap concentration (ppm) } \\
\cline { 2 - 3 } & $\mathbf{N O}_{\mathbf{3}}$-N & $\mathbf{K}$ \\
\hline \hline Plants eight-inches tall & $1200-1400$ & $4500-5000$ \\
First open flowers & $1000-1400$ & $4500-5000$ \\
$50 \%$ flowers open & $1000-1200$ & $4000-4500$ \\
$100 \%$ flowers open & $900-1200$ & $3500-4000$ \\
Tops falling over & $600-900$ & $2500-3000$ \\
\hline
\end{tabular}


inject remaining $\mathrm{K}_{2} \mathrm{O}$ and nitrogen into side of bed (Table 3). In seepage irrigated potatoes, banded or infected fertilizer must be placed deep enough in the bed to reach the capillary fringe of the perched water table.

\section{PLANT TISSUE ANALYSIS}

Plant tissue analysis for potato is listed in Table 4. This data corresponds to nutrient concentrations in the most recently matured leaf of 10 inch tall plants.

\section{PETIOLE SAP TESTING}

Fresh sap can be pressed from leaf petioles and analyzed for nitrogen and potassium concentrations. Results can be used to make fertilizer adjustments within the first 40 days after planting. Application of fertilizer near or after full flower will not result in tuber yield increase. Sufficiency ranges for sap testing for potato are presented in Table 5.

\section{IRRIGATION}

Potato plant growth is peaks at or soon after full flower. The highest demand for water occurs in the growth stages leading up to full flower. Plant water requirements increase from about $40 \%$ of ETo (see Chapter 8, Table 1) during the initial plant growth stages to $110 \%$ of ETo at peak foliar growth and tuber development. Tubers bulk rapidly after full flower when the foliage begins to senesce. Plant water use decreases to about $70 \%$ ETo. The depth of the perched water table in the seepage irrigated potatoes should be carefully maintained. The perched water table should be dropped before expected periods of heavy rainfall. Over irrigation late in the season can cause lenticels to expand detracting from fresh market tuber quality. In addition, over irrigation late in the season can lower specific gravity in chipping potatoes.

\section{WEED MANAGEMENT}

Weed control early in the season is important to maximize tuber yield and quality. A combination of herbicide application and working potato acreage will reduce weed pressure. Care should be taken to implement a weed control program that reduces weed pressure late in the season after foliage begins senesces. Failure of a weed control program late in the season will impact tuber bulking and the ease at which potatoes can be harvested. Water furrows should be maintained weed free as they can serve as a weed seed bank to re-infest the planted acreage. Herbicides labeled for weed control in potatoes are listed in Table 6.

\section{POTATO VINE DESICCANTS}

Potatoes grown in Florida fit into two marketing niches. A few potato varieties are grown for the processing market (chip or diced). For the processing market, it is often not necessary to produce a fully mature tuber with excellent skin quality as the potato will be processed shortly after harvest. However, many tubers in Florida enter the fresh market. Fresh market tubers are sold on appearance and taste. It is important for these tubers to have excellent skin quality and the ability to maintain quality for a short period of time.

Non-mature tubers will "skin" when harvested. Skinned tubers appear untidy due to bits of protruding skin. Skinned areas will also discolor turning from tan to dark brown. Non-mature tubers also lose significantly more weight than unskinned tubers in storage and transit. Skinned areas are sites of soft rot infection resulting in rejected loads.

Tubers can be induced to mature in the field by killing the potato vines either mechanically, with herbicides, or a combination of both. Rapid killing of vines under stressful (water or heat) conditions can result in discoloration of the tuber vascular tissue. Discoloration does not increase in storage or affect storage quality.

Killing the potato vines induces tubers to mature rapidly and causes the periderm to set. Tubers should remain in the field at least 14 to 21 days after vine kill and dependent on herbicide label information. The longer the period between vine kill and harvest, the less chance tubers will skin at harvest. The time it takes for tubers to mature after vine kill is variety dependent. A small plot of tubers should be dug periodically by hand and rubbed to test for skin slippage. It is difficult to get the skin to slip on mature tubers. It will take tubers longer to mature when plants are killed under active growing conditions (vines green and vigorous) compared to tubers under senescing vines.

When vines are killed, sunburning and/or greening can affect tubers not sufficiently covered with soil. Hilling soil around the plant to keep tubers covered is important. Vine desiccants are listed in Table 7. 


\section{DISEASE MANAGEMENT}

Chemicals approved for disease management of potato are listed in Table 8.

\section{PRODUCTION COSTS}

Production costs for chip and table potatoes in major Florida potato growing areas are given in Table 10 (Hastings-chip) and Table 11 (Hastings-table).

\section{INSECT MANAGEMENT}

Table 9 outlines the insecticides approved for use on insects attacking potato.

Table 6. Chemical weed controls: potatoes.

\begin{tabular}{|c|c|c|c|c|}
\hline \multirow[b]{2}{*}{ Herbicide } & \multirow[b]{2}{*}{ Labeled crops } & \multirow{2}{*}{$\begin{array}{l}\text { Time of } \\
\text { application to crop }\end{array}$} & \multicolumn{2}{|c|}{ Rate (Ibs. Al./Acre) } \\
\hline & & & Mineral & Muck \\
\hline $\begin{array}{l}\text { Carfentrazone } \\
\text { (Aim) }\end{array}$ & Potatoes & $\begin{array}{l}\text { Directed-hooded } \\
\text { row-middles }\end{array}$ & $0.008-0.025$ & $0.008-0.025$ \\
\hline \multicolumn{5}{|c|}{$\begin{array}{l}\text { Remarks: Aim may be applied as a post-directed hooded burn-down application to emerged broadleaf weeds in row middles. Aim is not } \\
\text { labeled for grassy weeds. May be tank mixed with other herbicides registerred for this treatment pattern. May be applied at } 0.33 \mathrm{oz}(0.008 \mathrm{lb} \\
\text { ai) to } 1 \mathrm{oz}(0.025 \mathrm{lb} \text { ai). Use a quality spray adjuvant such as crop oil concentrate (coc) or non-ionic surfactant (nis) at recommended rates. }\end{array}$} \\
\hline $\begin{array}{l}\text { Carfentrazone } \\
\text { (Aim) }\end{array}$ & Potatoes & $\begin{array}{l}\text { Preplant } \\
\text { Directed-hooded } \\
\text { Row-middles }\end{array}$ & 0.031 & 0.031 \\
\hline \multicolumn{5}{|c|}{$\begin{array}{l}\text { Remarks: Aim may be applied as a preplant burndown treatment and/or as a post-directed hooded application to row middles for the burn- } \\
\text { down of emerged broadleaf weeds. May be tank mixed with other registered herbicides. May be applied at up to } 2 \text { oz ( } 0.031 \mathrm{lb} \text { ai). Use a } \\
\text { quality spray adjuvant such as crop oil concentrate (coc) or non-ionic surfactant at recommended rates. }\end{array}$} \\
\hline $\begin{array}{l}\text { Clethodim } \\
\text { (Select) }\end{array}$ & Potatoes & Postemergence & $0.1-0.25$ & $0.1-0.25$ \\
\hline
\end{tabular}
mended heights. For control of annual grasses, use 6 to $16 \mathrm{fl}$. oz/A, for perennial grasses, use 8 to $16 \mathrm{fl} \mathrm{oz/A}$.

\begin{tabular}{llccc}
\hline \hline DCPA & Potato & Preemergence or early layby & ---
\end{tabular}

(Dacthal W-75)

Remarks: Controls germinating annuals. Apply to moist soil. Note label precautions of replanting non-registered crops within 8 months.

\begin{tabular}{lllll}
\hline EPTC & Potato & Postemergence or early layby; & 3.0 & --- \\
(Eptam 7E) & & Preplant, Dragoff, Layby & 3.0 & --
\end{tabular}

(Eptam 10G)

Remarks: Granular formulation may be applied Preplant incorporated, at Dragoff and incorporated or at Layby and incorporated into clean cultivated soil. Emulsifiable formulation should not be applied on winter and early spring potatoes. Apply only after potatoes have emerged and true leaves have formed or at layby. There is a 45-day preharvest interval for application.

\begin{tabular}{llll}
\hline S-Metolachlor & Potato & Preemergence; & $.95-1.9$ \\
(Dual Magnum) & & Preplant incorporated; & -- \\
& & Postplant incorporated
\end{tabular}

Postplant incorporated

Remarks: Applications must be made before crop emergence. Preemergence and postplant incorporated should be made after drag off but before potato or weed emergence. May be tank mixed with Sencore/Prowe as preemergence treatment. When used alone, label states control of many grasses and broadleaf weeds including crabgrass, fall panicum, goosegrass, signalgrass, yellow nutsedge, galensoga, pigweed and Florida pusley. Note: Under prolonged cool, wet conditions, minor foliage injury has been seen.

\begin{tabular}{llcl}
\hline \hline Metribuzin & Potato & Preemergence & $0.5-1.0$
\end{tabular}

(Sencor DF) (Sencor 4)

Remarks: Apply to soil surface after drag-off but before crop emergence. Do not incorporate. Use lower rate on sandy soil.

\begin{tabular}{llll}
\hline Metribuzin (Lexone DF) & Potato & Postemergence & $0.25-0.5$
\end{tabular}

(Sencor DF) (Sencor 4)

Remarks: Not to be used on early maturing white or red skinned varieties. Apply only if there have been 3 consecutive days of sunny weather. Treat before weeds are 1" tall. Do not apply within 60 days of harvest. Split applications of pre plus postemergence may be made. Do not use more than $1 \mathrm{lb}$. per season. 
Table 6. Continued.

\begin{tabular}{|c|c|c|c|c|}
\hline \multirow[b]{2}{*}{ Herbicide } & \multirow[b]{2}{*}{ Labeled crops } & \multirow{2}{*}{$\begin{array}{l}\text { Time of } \\
\text { application to crop }\end{array}$} & \multicolumn{2}{|c|}{ Rate (Ibs. Al./Acre) } \\
\hline & & & Mineral & Muck \\
\hline $\begin{array}{l}\text { Paraquat } \\
\text { (Gramoxone Inteon) } \\
\text { (Firestorm) }\end{array}$ & Potato & Preemergence & 0.47 & 0.47 \\
\hline \multicolumn{5}{|c|}{ Remarks: Controls emerged weed seedlings. Apply after planting, but before potatoes emerge. Use a non-ionic spreader. } \\
\hline $\begin{array}{l}\text { Pelargonic Acid } \\
\text { (Scythe) }\end{array}$ & Potato & $\begin{array}{l}\text { Preplant } \\
\text { Preemergence } \\
\text { Directed-Shielded }\end{array}$ & $3-10 \% \mathrm{v} / \mathrm{v}$ & $3-10 \% \mathrm{v} / \mathrm{v}$ \\
\hline \multicolumn{5}{|c|}{$\begin{array}{l}\text { Remarks: Product is a contact, nonselective, foliar herbicide. There is no residual activity. May be tank mixed with soil residual herbi- } \\
\text { cides. Consult label for rates and timings of applications. }\end{array}$} \\
\hline & Potato & $\begin{array}{l}\text { Preemergence; } \\
\text { Preemergence Incorpo }\end{array}$ & 0.75 & --- \\
\hline \multicolumn{5}{|c|}{$\begin{array}{l}\text { Remarks: May be applied after planting but before potatoes and weeds emerge or after drag-off. Most effective when incorporated by } \\
\text { rainfall or mechanically into top } 1 \text { to } 20 \text { of soil within } 7 \text { days after application. Will not control established weeds. May also be applied } \\
\text { early postemergence (from emergence to } 6 \text {-inch stage of growth). Use this application on trial basis only. May be tank mixed with } \\
\text { Sencore/Lexone, Eptam. Label states not for use on peat or muck soils. }\end{array}$} \\
\hline $\begin{array}{l}\text { Rimsulfuron } \\
\text { (Matrix) }\end{array}$ & Potato & $\begin{array}{l}\text { Preplant } \\
\text { Preemergence } \\
\text { Directed-Shielded }\end{array}$ & $0.25-0.38 \mathrm{oz}$ & $0.25-0.380 z$ \\
\hline \multicolumn{5}{|c|}{$\begin{array}{l}\text { Remarks: Apply at a rate of } 1 \text { to } 20 z \text { of product to clean soil following hilling or drag-off. Product must be activated by irrigation or rain- } \\
\text { fall with } 5 \text { days. Apply postemergence to actively growing small weeds after crop emergence. Add as non-ionic surfactant to postemer- } \\
\text { gence applications. Do not apply within } 60 \text { days of harvest. Do not exceed } 2.0 \text { oz product per acre/growing season. Preemergence tank } \\
\text { mixes of Matrix with Lexone, Eptam, Prowl, Lorox or Dual are labeled. Postemergence tank mixes of Matrix plus Lexone an Eptam are } \\
\text { labeled. Note and follow rotational crop guidelines. }\end{array}$} \\
\hline Sethoxydim (Poast) & Potato & Postemergence & $0.188-0.28$ & $0.188-0.28$ \\
\hline \multicolumn{5}{|c|}{$\begin{array}{l}\text { Remarks: Controls actively growing grass weeds. A total of } 5 \text { pts. product per acre may be applied in one season. Do not apply within } 30 \\
\text { days of harvest. Apply in } 5 \text { to } 20 \text { gals. of water adding } 2 \text { pts. of crop oil concentrate per acre. Unsatisfactory results may occur if applied } \\
\text { to grasses under stress. Use } 0.188 \mathrm{lb} \text { ai ( } 1 \text { pt.) to seedling grasses and up to } 0.28 \mathrm{lb} \text { ai (1.5 pts.) to perennial grasses emerging from rhi- } \\
\text { zomes, etc. Consult label for grass species and arowth stage for best control. }\end{array}$} \\
\hline
\end{tabular}

Table 7. Chemical desiccants for potato production.

\begin{tabular}{|c|c|c|c|c|c|}
\hline Active Ingredient & Common Name & Manufacturer & Product Rate & PH Interval1 & Relative Desc. Rate² \\
\hline Carfentrazone & AIM & FMC & $3.2-5.8 \mathrm{fl} \mathrm{oz/A}$ & 7 days & Fast \\
\hline Diquat & Reglone & Syngenta & $1-2 \mathrm{pt} / \mathrm{A}$ & 7 days & Fast \\
\hline Endothal & Desicate II & Cerexagri & $1.5-2 \mathrm{qt} / \mathrm{A}$ & 10 days & Slow \\
\hline Pelargonic Acid & Scythe & Dow & 7-10\% sol. & 1 day & Fast \\
\hline Pyraflufen & ET & Nichino & $2.75-5.5 \mathrm{fl} \mathrm{oz/A}$ & 14 days & Slow \\
\hline \multicolumn{6}{|c|}{$\begin{array}{l}1 \text { Preharvest interval is the minimum time between application and harvest. It is not necessarily the time required to achieve tuber matu } \\
\text { rity and good skin-set. }\end{array}$} \\
\hline
\end{tabular}


Table 8. Disease management for potato.

\begin{tabular}{|c|c|c|c|c|c|c|}
\hline Chemical & $\begin{array}{l}\text { Fungicide } \\
\text { Group }\end{array}$ & $\frac{\text { Maximum }}{\text { Application }}$ & $\begin{array}{l}\text { Rate/Acre/ } \\
\text { Season }\end{array}$ & $\begin{array}{l}\text { Min. Days } \\
\text { to Harvest }\end{array}$ & $\begin{array}{l}\text { Pertinent Diseases } \\
\text { or Pathogens }\end{array}$ & Remarks \\
\hline $\begin{array}{l}\text { Dithane M45, } \\
\text { Penncozeb 80WP } \\
\text { (Mancozeb) }\end{array}$ & M3 & $2 \mathrm{lb}$ & $14 \mathrm{lb}$ & 3 & $\begin{array}{l}\text { Early Blight } \\
\text { Late Blight }\end{array}$ & $\begin{array}{l}1.25 \mathrm{lb} / 50 \text { gal. water for seed piece } \\
\text { treatment. Allow to dry and do not } \\
\text { use as livestock feed. }\end{array}$ \\
\hline $\begin{array}{l}\text { Dithane F45 } \\
\text { Rainshield or } \\
\text { Manzate Flowable } \\
\text { (Mancozeb) }\end{array}$ & M3 & $1.6 \mathrm{qt}$ & $11.2 \mathrm{qt}$ & 3 & $\begin{array}{l}\text { Early blight } \\
\text { Late blight }\end{array}$ & $\begin{array}{l}1 \mathrm{qt} / 50 \text { gal. water for seed piece } \\
\text { treatment. Allow to dry and do not } \\
\text { use as livestock feed. }\end{array}$ \\
\hline $\begin{array}{l}\text { Penncozeb 75DF, } \\
\text { Manzate 75DF, } \\
\text { Manzate Pro-Stick } \\
\text { (Mancozeb) }\end{array}$ & & $2 \mathrm{lb}$ & $15 \mathrm{lb}$ & 3 & $\begin{array}{l}\text { Early blight } \\
\text { Late blight }\end{array}$ & $\begin{array}{l}1.25 \mathrm{lbs} / 50 \text { gal water for seed } \\
\text { piece treatment. Allow to dry and } \\
\text { do not use as livestock feed. }\end{array}$ \\
\hline $\begin{array}{l}\text { Manex } \\
\text { (Maneb) }\end{array}$ & M3 & $1.6 \mathrm{qt}$ & $11.2 \mathrm{qt}$ & 3 & $\begin{array}{l}\text { Early blight } \\
\text { Late blight }\end{array}$ & $\begin{array}{l}0.8 \mathrm{qt} . / 10 \mathrm{gal} \text { of water for seed } \\
\text { piece treatment. Allow to dry and } \\
\text { do not use as livestock feed. }\end{array}$ \\
\hline $\begin{array}{l}\text { Maneb 80WP } \\
\text { (Maneb) }\end{array}$ & M3 & $2 \mathrm{lb}$ & $14 \mathrm{lb}$ & 3 & $\begin{array}{l}\text { Early blight } \\
\text { Late blight }\end{array}$ & $\begin{array}{l}1 \mathrm{lb} / 10 \text { gal. water for seed piece } \\
\text { treatment. Allow to dry and do not } \\
\text { use as livestock feed. }\end{array}$ \\
\hline $\begin{array}{l}\text { Ridomil Gold Copper } \\
64.8 \text { W } \\
\text { (Copper hydroxide; } \\
\text { Mefenoxam) }\end{array}$ & 4 & $2 \mathrm{lb}$ & $7.5 \mathrm{lb}$ & 14 & Late blight & $\begin{array}{l}\text { Limit is } 3 \text { appl./crop of this prod- } \\
\text { uct } \& \text { other Ridomil products Add } \\
\text { protectant fungicide, see label. }\end{array}$ \\
\hline $\begin{array}{l}\text { Maneb 75DF } \\
\text { (Maneb) }\end{array}$ & M3 & $2 \mathrm{lb}$ & $14.9 \mathrm{lb}$ & 3 & $\begin{array}{l}\text { Late blight } \\
\text { Early blight }\end{array}$ & Same as for Maneb 80 WP \\
\hline $\begin{array}{l}\text { Rovral 4F and } \\
\text { Iprodione 4L } \\
\text { (Iprodione) }\end{array}$ & 2 & $2 \mathrm{pt}$ & $8 \mathrm{pt}$ & 14 & $\begin{array}{l}\text { Early blight } \\
\text { Sclerotinia }\end{array}$ & $\begin{array}{l}\text { Limit is } 4 \text { appl./crop } \\
\text { Limit is } 4 \text { appl./crop }\end{array}$ \\
\hline $\begin{array}{l}\text { Ridomil Gold Bravo } \\
76.4 \mathrm{~W}\end{array}$ & M5 and 4 & $2 \mathrm{lb}$ & $8 \mathrm{lb}$ & 14 & $\begin{array}{l}\text { Late blight } \\
\text { Early blight }\end{array}$ & \\
\hline $\begin{array}{l}\text { Bravo Ultrex } \\
\text { (Chlorothalonil) }\end{array}$ & M5 & $1.36 \mathrm{lb}$ & $13.6 \mathrm{lb}$ & 7 & $\begin{array}{l}\text { Late blight } \\
\text { Early blight }\end{array}$ & $\begin{array}{l}\text { Up to } 0.7 . \mathrm{lb} \text { is allowed before } \\
\text { vines close or before } 18 \text { severity } \\
\text { values occur }\end{array}$ \\
\hline $\begin{array}{l}\text { Equus 720SST } \\
\text { (Cholorthalonil) }\end{array}$ & M5 & $1.5 \mathrm{pt}$ & $15 \mathrm{pt}$ & 7 & $\begin{array}{l}\text { Late blight } \\
\text { Early blight }\end{array}$ & Same as Bravo Weather Stik \\
\hline $\begin{array}{l}\text { Polyram 80DF } \\
\text { (Metiram) }\end{array}$ & M3 & $2 \mathrm{lb}$ & $14 \mathrm{lb}$ & 3 & $\begin{array}{l}\text { Late blight } \\
\text { Early blight }\end{array}$ & Limit is 7 appl./season \\
\hline $\begin{array}{l}\text { Quadris 2.08FL } \\
\text { (Azoxystrobin) }\end{array}$ & 11 & $15.4 \mathrm{fl} \mathrm{oz}$ & $3.75 \mathrm{qt}$ & 14 & $\begin{array}{l}\text { Late blight } \\
\text { Early blight } \\
\text { Various, see label }\end{array}$ & $\begin{array}{l}\text { Limit is } 6 \text { appl./crop/acre \& alter- } \\
\text { nate chemistry }\end{array}$ \\
\hline $\begin{array}{l}\text { Amistar 80DF } \\
\text { (Azoxystrobin) }\end{array}$ & 11 & $50 z$ & $2.5 \mathrm{lb}$ & 14 & Same as Quadris & Same as Quadris \\
\hline $\begin{array}{l}\text { ManKocide } 61.1 \mathrm{DF} \\
\text { (Copper hydroxide; } \\
\text { Mancozeb) }\end{array}$ & $M 1 \& M 3$ & $5.3 \mathrm{lb}$ & $74.66 \mathrm{lb}$ & 3 & $\begin{array}{l}\text { Early blight } \\
\text { Late blight }\end{array}$ & \\
\hline $\begin{array}{l}\text { Super-Tin 80WP1 } \\
\text { (Triphenyltin hydrox- } \\
\text { ide) }\end{array}$ & 30 & $3.75 \mathrm{oz}$ & $15 \mathrm{oz}$ & 7 & $\begin{array}{l}\text { Early blight } \\
\text { Late blight }\end{array}$ & $\begin{array}{l}\text { For use with closed tractor cabs } \\
\text { only. }\end{array}$ \\
\hline $\begin{array}{l}\text { Bravo Weather Stik } \\
6 \mathrm{~L} \\
\text { (Chlorothalonil) }\end{array}$ & M5 & $1.5 \mathrm{pt}$ & $15 \mathrm{pt}$ & 7 & $\begin{array}{l}\text { Early blight } \\
\text { Late blight }\end{array}$ & $\begin{array}{l}\text { Up to } 3 / 4 \text { pt. allowed before vines } \\
\text { close between rows or before } 18 \\
\text { disease severity values occur. }\end{array}$ \\
\hline
\end{tabular}


Table 8. Continued.

\begin{tabular}{|c|c|c|c|c|c|c|}
\hline Chemical & $\begin{array}{l}\text { Fungicide } \\
\text { Group }\end{array}$ & $\frac{\text { Maximum }}{\text { Application }}$ & $\begin{array}{l}\text { Rate/Acre/ } \\
\text { Season }\end{array}$ & $\begin{array}{l}\text { Min. Days } \\
\text { to Harvest }\end{array}$ & $\begin{array}{l}\text { Pertinent Diseases } \\
\text { or Pathogens }\end{array}$ & Remarks \\
\hline $\begin{array}{l}\text { Curzate 70DF } \\
\text { (Cymoxanil) }\end{array}$ & 27 & $3.20 z$ & $22.4 \mathrm{oz}$ & 14 & Late blight & $\begin{array}{l}\text { Limit is } 7 \text { apps/crop. Use in com- } \\
\text { bination with a protectant fungi- } \\
\text { cide. It is best to alternate Curzate } \\
\text { with other fungicides such as } \\
\text { mancozeb or chlorothalonil. Do not } \\
\text { replant area to other crops within } \\
30 \text { days of treatment. }\end{array}$ \\
\hline $\begin{array}{l}\text { Topsin M 70WP } \\
\text { (Thiophanate- } \\
\text { methyl) }\end{array}$ & 1 & $1-11 / 2 \mathrm{lb} / \mathrm{A}$ & $4 \mathrm{lb}$ & $\begin{array}{l}21 \\
3\end{array}$ & $\begin{array}{l}\text { White Mold } \\
\text { (Sclerotinia) }\end{array}$ & $\begin{array}{l}\text { May be tank mixed with other fun- } \\
\text { gicides labeled for early and late } \\
\text { blight control. Aerial application is } \\
\text { not recommended. }\end{array}$ \\
\hline $\begin{array}{l}\text { Gavel 75DF } \\
\text { (Mancozeb; } \\
\text { Zoxamide) }\end{array}$ & M3 \& 22 & $2.0 \mathrm{lb}$ & $12 \mathrm{lb}$ & & $\begin{array}{l}\text { Early blight } \\
\text { Late blight }\end{array}$ & $\begin{array}{l}\text { This product contains } 66.7 \% \text { man- } \\
\text { cozeb so do not exceed maximum } \\
\text { allowed for mancozeb considering } \\
\text { this and other mancozeb-contain- } \\
\text { ing products. A } 30 \text { day rotational } \\
\text { limit for non-labelled crops exists } \\
\text { for this product }\end{array}$ \\
\hline $\begin{array}{l}\text { Headline 2.09F } \\
\text { (Pyraclostrobin) }\end{array}$ & 11 & $12 \mathrm{fl} \mathrm{oz}$ & $72 \mathrm{fl} \mathrm{oz}$ & 3 & $\begin{array}{l}\text { Early blight } \\
\text { Late blight }\end{array}$ & $\begin{array}{l}6 \text { appl. Maximum. Alternate with } \\
\text { other fungicide type between } \\
\text { appls. }\end{array}$ \\
\hline $\begin{array}{l}\text { Heritage } \\
\text { (Axoxystrobin) }\end{array}$ & 11 & $9.60 z$ & $4.0 \mathrm{lb}$ & 14 & $\begin{array}{l}\text { Early blight } \\
\text { Late Blight }\end{array}$ & $\begin{array}{l}6 \text { appl. Maximum. Alternate with } \\
\text { other fungicide type between } \\
\text { appls. }\end{array}$ \\
\hline $\begin{array}{l}\text { Gem 500SC } \\
\text { (Trifoxystrobin) }\end{array}$ & 11 & $3.8 \mathrm{fl} \mathrm{oz}$ & $23 \mathrm{fl} .0 \mathrm{z}$ & 7 & $\begin{array}{l}\text { Early blight } \\
\text { Late Blight }\end{array}$ & $\begin{array}{l}\text { Limit is } 6 \text { appl./crop and alternate } \\
\text { chemistry }\end{array}$ \\
\hline $\begin{array}{l}\text { Endura 70WP } \\
\text { (Boscalid) }\end{array}$ & 7 & $10 \mathrm{oz}$ & $20.5 \mathrm{oz}$ & 30 & Early blight & $\begin{array}{l}\text { Limit is } 4 \text { appl./crop \& alternate } \\
\text { chemistry }\end{array}$ \\
\hline $\begin{array}{l}\text { Acrobat } \\
\text { (Dimethomorph) }\end{array}$ & 40 & $6.4 \mathrm{oz}$ & $32 \mathrm{oz}$ & 4 & $\begin{array}{l}\text { Late blight } \\
\text { Tuber blight }\end{array}$ & \\
\hline $\begin{array}{l}\text { Agri-tin } \\
\text { (Triphenyltin hydrox- } \\
\text { ide) }\end{array}$ & 30 & $3.75 \mathrm{oz}$ & 11.25 & 7 & Early blight Late blight & \\
\hline $\begin{array}{l}\text { Agri-Mycin and } \\
\text { Streptrol } \\
\text { (Streptomycin) }\end{array}$ & 25 & 100 ppm & & & & Seed treatment \\
\hline $\begin{array}{l}\text { Blocker 4F } \\
\text { (Pentachloronitro - } \\
\text { benzene (PCNB) }\end{array}$ & 14 & $10 \mathrm{pt} / \mathrm{A}$ & $20 \mathrm{pt}$ & & $\begin{array}{l}\text { Stem canker } \\
\text { Black scurf } \\
\text { Late blight }\end{array}$ & Apply at planting \\
\hline $\begin{array}{l}\text { Echo } 720 \\
\text { (Chlorothalonil) }\end{array}$ & M5 & $1.5 \mathrm{pt}$ & $\begin{array}{l}11.25 \mathrm{lb} \\
\text { ai/A }\end{array}$ & 7 & Early blight & \\
\hline $\begin{array}{l}\text { Echo 90DF } \\
\text { (Chlorothalonil) }\end{array}$ & M5 & $1.25 \mathrm{lb}$ & & & Late blight & \\
\hline $\begin{array}{l}\text { Equus DF } \\
\text { (Chlorothalonil) }\end{array}$ & M5 & $1.36 \mathrm{lb}$ & $13.6 \mathrm{lb}$ & 7 & $\begin{array}{l}\text { Early blight } \\
\text { Late blight } \\
\text { Botrytis }\end{array}$ & \\
\hline $\begin{array}{l}\text { Maxim 4FS } \\
\text { (Fludioxonil) }\end{array}$ & 12 & $\begin{array}{l}0.16 \\
0 z / 100 \mathrm{lb} \\
\text { seed }\end{array}$ & & & & $\begin{array}{l}\text { Seed treatment. Must be made } \\
\text { using specific equipment. See } \\
\text { label. }\end{array}$ \\
\hline $\begin{array}{l}\text { Maxim Potato Seed } \\
\text { Protectant } \\
\text { (Fludioxonil) }\end{array}$ & 12 & $\begin{array}{l}0.5 \mathrm{lb} / 100 \\
\mathrm{lb} \text { seed }\end{array}$ & & & $\begin{array}{l}\text { Fusarium } \\
\text { Stem Canker }\end{array}$ & Seed treatment \\
\hline $\begin{array}{l}\text { Moncut 70DF } \\
\text { (Flutolanil) }\end{array}$ & 7 & $1.1 \mathrm{lb}$ & $3.5 \mathrm{pt}$ & 14 & Rhizoctonia & In-furrow use only \\
\hline
\end{tabular}


Table 8. Continued.

\begin{tabular}{|c|c|c|c|c|c|c|}
\hline Chemical & $\begin{array}{l}\text { Fungicide } \\
\text { Group }\end{array}$ & $\frac{\text { Maximum }}{\text { Application }}$ & $\frac{\text { Rate/Acre/ }}{\text { Season }}$ & $\begin{array}{l}\text { Min. Days } \\
\text { to Harvest }\end{array}$ & $\begin{array}{l}\text { Pertinent Diseases } \\
\text { or Pathogens }\end{array}$ & Remarks \\
\hline $\begin{array}{l}\text { Omega 500F } \\
\text { (Fluazinam) }\end{array}$ & 29 & $80 z$ & & & $\begin{array}{l}\text { Late blight } \\
\text { White mold }\end{array}$ & \\
\hline $\begin{array}{l}\text { Potato Seed Treater } \\
6 \% \text { and Potato Seed } \\
\text { Treater PS } \\
\text { (Mancozeb) }\end{array}$ & M3 & $\begin{array}{l}1 \mathrm{lb} / 100 \mathrm{lb} \\
\text { seed }\end{array}$ & & & Fusarium & Seed treatment \\
\hline $\begin{array}{l}\text { Ranman } \\
\text { (Cyazofamid) }\end{array}$ & 21 & $\begin{array}{l}2.75 \mathrm{fl} \\
\mathrm{Oz} / \mathrm{A}\end{array}$ & $27.5 \mathrm{fl} \mathrm{oz}$ & 7 & Late blight & $\begin{array}{l}\text { Alternate sprays with a fungicide } \\
\text { with a different mode of action. } \\
\text { Follow label directions }\end{array}$ \\
\hline $\begin{array}{l}\text { Reason 500SC } \\
\text { (Fenamidone) }\end{array}$ & 11 & $8.2 \mathrm{fl} \mathrm{oz}$ & $24.6 \mathrm{fl} \mathrm{oz}$ & 14 & $\begin{array}{l}\text { Late blight } \\
\text { Early blight }\end{array}$ & $\begin{array}{l}\text { Alternate sprays with a fungicide } \\
\text { with a different mode of action. } \\
\text { Follow label directions }\end{array}$ \\
\hline $\begin{array}{l}\text { Previcur Flex } \\
\text { (Promocarb hydro- } \\
\text { chloride) }\end{array}$ & U & $1.2 \mathrm{pt}$ & $6.0 \mathrm{pt}$ & 14 & $\begin{array}{l}\text { Late blight } \\
\text { Early blight }\end{array}$ & $\begin{array}{l}\text { Use with a tank mix. See label for } \\
\text { seed piece treatment. }\end{array}$ \\
\hline $\begin{array}{l}\text { Ridomil Gold EC } \\
\text { (Mefenoxam) }\end{array}$ & 4 & $\begin{array}{l}\text { Apply } 0.42 \\
\text { oz/1000 } \\
\text { linear } \mathrm{ft}\end{array}$ & & & $\begin{array}{l}\text { Pythium and } \\
\text { Phytophthora damp- } \\
\text { ing-off }\end{array}$ & Apply at planting \\
\hline $\begin{array}{l}\text { Ridomil Gold MZ } \\
\text { (Mancozeb; } \\
\text { Mefenoxam) }\end{array}$ & M3 \& 4 & $2.5 \mathrm{lb}$ & $7.5 \mathrm{lb}$ & 3 & $\begin{array}{l}\text { Early blight } \\
\text { Late blight }\end{array}$ & \\
\hline $\begin{array}{l}\text { Scala SC } \\
\text { (Pyrimethanil) }\end{array}$ & 9 & $7 \mathrm{oz}$ & $350 z$ & 7 & Early blight & \\
\hline $\begin{array}{l}\text { Serenade ASO } \\
\text { (Bacillus subtilis } \\
\text { strain QST 713) }\end{array}$ & & $6 \mathrm{qt}$ & & 0 & $\begin{array}{l}\text { Early blight } \\
\text { Late blight }\end{array}$ & \\
\hline $\begin{array}{l}\text { Serenade Max } \\
\text { (Bacillus subtilis } \\
\text { strain QST 713) }\end{array}$ & & $3 \mathrm{lb}$ & & 0 & $\begin{array}{l}\text { Early blight } \\
\text { Late blight }\end{array}$ & \\
\hline $\begin{array}{l}\text { Sonata } \\
\text { (Bacillus pumilus } \\
\text { strain QST 2808) }\end{array}$ & & $4 \mathrm{qt}$ & & 0 & $\begin{array}{l}\text { Early blight } \\
\text { Late blight }\end{array}$ & \\
\hline $\begin{array}{l}\text { Sulfur (Various } \\
\text { brands) } \\
\text { (Sulfur) }\end{array}$ & M2 & & & & & $\begin{array}{l}\text { Do not apply in warm weather. Do } \\
\text { not apply within } 2 \text { weeks of an oil } \\
\text { spray. }\end{array}$ \\
\hline Tanos & $27 \& 11$ & $80 z$ & $48 \mathrm{oz}$ & 14 & $\begin{array}{l}\text { Early blight } \\
\text { Late blight }\end{array}$ & $\begin{array}{l}\text { Do not make consecutive applica- } \\
\text { tions. Rotate to material with dif- } \\
\text { ferent mode of action }\end{array}$ \\
\hline $\begin{array}{l}\text { (Cymoxanil; } \\
\text { Famoxadone) }\end{array}$ & & & & & Late blight & \\
\hline $\begin{array}{l}\text { Terraclor 75WP } \\
\text { (Pentachloronitro- } \\
\text { benzene (PCNB)) }\end{array}$ & 14 & $6.66 \mathrm{lb}$ & & & Rhizoctonia & At planting \\
\hline $\begin{array}{l}\text { Terraclor F } \\
\text { (Pentachloronitro- } \\
\text { benzene (PCNB)) }\end{array}$ & 14 & $\begin{array}{l}10.4 \mathrm{oz} \\
1000 \mathrm{lin}- \\
\text { ear ft }\end{array}$ & & & Rhizoctonia & At planting \\
\hline $\begin{array}{l}\text { Thiophanate Methyl } \\
\text { 85WDG } \\
\text { (Thiophanate- } \\
\text { methyl) }\end{array}$ & 1 & $1.2 \mathrm{lb}$ & $3.2 \mathrm{lb}$ & 21 & White mold & \\
\hline
\end{tabular}


Table 9. Insecticides approved for use on insects attacking potatoes.

\begin{tabular}{|c|c|c|c|c|c|c|}
\hline $\begin{array}{l}\text { Trade Name } \\
\text { (Common Name) }\end{array}$ & $\begin{array}{l}\text { Rate } \\
\text { (product/acre) }\end{array}$ & $\begin{array}{l}\text { REI } \\
\text { (hours) }\end{array}$ & $\begin{array}{l}\text { Days to } \\
\text { Harvest }\end{array}$ & Insects & $\begin{array}{l}\text { MOA } \\
\text { Code }^{1}\end{array}$ & Notes \\
\hline $\begin{array}{l}\text { *Ambush 25W } \\
\text { (permethin) }\end{array}$ & $3.2-12.80 z$ & 12 & 14 & $\begin{array}{l}\text { cabbage looper, Colorado } \\
\text { potato beetle, potato } \\
\text { aphid, potato flea beetle, } \\
\text { potato leafhopper, potato } \\
\text { tuberworm }\end{array}$ & 3 & $\begin{array}{l}\text { Do not apply more than } 1.6 \mathrm{lb} \\
\text { active ingredient per season } \\
(102.4 \text { oz). }\end{array}$ \\
\hline $\begin{array}{l}\text { *Asana XL (0.66 EC) } \\
\text { (esfenvalerate) }\end{array}$ & $2.9-9.6 \mathrm{fl} \mathrm{oz}$ & 12 & 7 & $\begin{array}{l}\text { beet armyworm (aids in } \\
\text { control), cabbage looper, } \\
\text { Colorado potato beetle, } \\
\text { cucumber beetles (adults), } \\
\text { cutworms, flea beetles, } \\
\text { grasshoppers, potato } \\
\text { aphid, potato leafhopper, } \\
\text { potato tuberworm, tar- } \\
\text { nished plant bug }\end{array}$ & 3 & $\begin{array}{l}\text { Do not apply more than } 0.35 \mathrm{lb} \\
\text { ai/acre per season ( } 7 \text { applications } \\
\text { at highest rate). }\end{array}$ \\
\hline $\begin{array}{l}\text { Assail 70WP } \\
\text { (acetomiprid) }\end{array}$ & $0.6-1.7 \mathrm{oz}$ & 12 & 7 & $\begin{array}{l}\text { aphids, Colorado potato } \\
\text { beetle, leafhoppers, flea } \\
\text { beetle }\end{array}$ & $4 \mathrm{~A}$ & $\begin{array}{l}\text { Do not make more than } 4 \text { applica- } \\
\text { tions per season. Do no exceed } \\
\text { a total of } 0.3 \mathrm{lb} \text { ai per acre per } \\
\text { season. }\end{array}$ \\
\hline Assail $30 \mathrm{SG}$ & $1.5-4.0 \mathrm{oz}$ & & & & & \\
\hline $\begin{array}{l}\text { Avaunt } \\
\text { (indoxacarb) }\end{array}$ & $2.5-6.0 \mathrm{oz}$ & 12 & 7 & $\begin{array}{l}\text { cabbage looper, Colorado } \\
\text { potato beetle }\end{array}$ & 22 & $\begin{array}{l}\text { Do not apply more than } 24 \text { oz/ } \\
\text { acre per crop. }\end{array}$ \\
\hline $\begin{array}{l}\text { Aza-Direct } \\
\text { (azadirachtin) }\end{array}$ & $\begin{array}{l}1-2 \mathrm{pts} \text {, up } \\
\text { to } 3.5 \mathrm{pts} \text {, if } \\
\text { needed }\end{array}$ & 4 & 0 & $\begin{array}{l}\text { aphids, beetles, caterpil- } \\
\text { lars, leafhoppers, leafmin- } \\
\text { ers, mites, stink bugs, } \\
\text { thrips, weevils, whiteflies }\end{array}$ & 26 & $\begin{array}{l}\text { Antifeedant, repellant, insect } \\
\text { growth regulator. OMRI-listed }{ }^{2} \text {. }\end{array}$ \\
\hline $\begin{array}{l}\text { Azatin XL } \\
\text { (azadirachtin) }\end{array}$ & $5-21 \mathrm{fl} \mathrm{oz}$ & 4 & 0 & $\begin{array}{l}\text { aphids, beetles, caterpil- } \\
\text { lars, leafhoppers, leafmin- } \\
\text { ers, thrips, weevils, } \\
\text { whiteflies }\end{array}$ & 26 & $\begin{array}{l}\text { Antifeedant, repellant, insect } \\
\text { growth regulator. }\end{array}$ \\
\hline $\begin{array}{l}\text { *Baythroid } 2 \\
\text { (cyfluthrin) }\end{array}$ & $0.8-2.8 \mathrm{fl} \mathrm{oz}$ & 12 & 0 & $\begin{array}{l}\text { cabbage looper, Colorado } \\
\text { potato beetle, cutworms, } \\
\text { flea beetles, potato leaf- } \\
\text { hopper, potato tuberworm, } \\
\text { tarnished plant bug }\end{array}$ & 3 & $\begin{array}{l}\text { Allow at least } 5 \text { days between } \\
\text { applications. A total of } 6 \text { appli- } \\
\text { cations and a maximum of } 16 \\
\text { oz may be applied per acre per } \\
\text { season. }\end{array}$ \\
\hline $\begin{array}{l}\text { Biobit HP } \\
\text { (Bacillus thuringiensis } \\
\text { subspecies kurstaki) }\end{array}$ & $0.5-2.0 \mathrm{lb}$ & 4 & 0 & $\begin{array}{l}\text { caterpillars (will not con- } \\
\text { trol large armyworms) }\end{array}$ & $11 \mathrm{~B} 2$ & 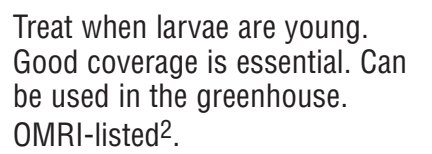 \\
\hline $\begin{array}{l}\text { BotaniGard } 22 \text { WP, ES } \\
\text { (Beauveria bassiana) }\end{array}$ & $\begin{array}{l}\text { WP: } \\
0.5-2 \mathrm{lb} / 100 \mathrm{gal} \\
\text { ES: } \\
0.5-2 \text { qts } / 100 \\
\text { gal }\end{array}$ & 4 & 0 & aphids, thrips, whiteflies & -- & $\begin{array}{l}\text { May be used in greenhouses. } \\
\text { Contact dealer for recommenda- } \\
\text { tions if an adjuvant must be used. } \\
\text { Not compatible in tank mix with } \\
\text { fungicides. }\end{array}$ \\
\hline $\begin{array}{l}\text { Clinch } \\
\text { (Abamectin) }\end{array}$ & $1 \mathrm{lb}$ & 12 & 0 & fire ants & 6 & $\begin{array}{l}\text { Apply when ants are actively for- } \\
\text { aging. Apply after dew or rainfall } \\
\text { has dried for maximum effective- } \\
\text { ness. Do not apply if rainfall is } \\
\text { anticipated within 4-6 hours. }\end{array}$ \\
\hline $\begin{array}{l}\text { Crymax WDG } \\
\text { (Bacillus thuringiensis } \\
\text { subspecies kurstaki) }\end{array}$ & $0.5-2.0 \mathrm{lb}$ & 4 & 0 & caterpillars & $11 \mathrm{~B} 2$ & $\begin{array}{l}\text { Use high rate for armyworms. } \\
\text { Treat when larvae are young. }\end{array}$ \\
\hline
\end{tabular}


Table 9. Continued.

\begin{tabular}{|c|c|c|c|c|c|c|}
\hline $\begin{array}{l}\text { Trade Name } \\
\text { (Common Name) }\end{array}$ & $\begin{array}{l}\text { Rate } \\
\text { (product/acre) }\end{array}$ & $\begin{array}{l}\text { REI } \\
\text { (hours) }\end{array}$ & $\begin{array}{l}\text { Days to } \\
\text { Harvest }\end{array}$ & Insects & $\begin{array}{l}\text { MOA } \\
\text { Code }^{1}\end{array}$ & Notes \\
\hline $\begin{array}{l}\text { Deliver } \\
\text { (Bacillus thuringiensis } \\
\text { subspecies kurstaki) }\end{array}$ & $0.25-1.5 \mathrm{lb}$ & 4 & 0 & caterpillars & 11B2 & $\begin{array}{l}\text { Use higher rates for armyworms. } \\
\text { OMRI-listed². }\end{array}$ \\
\hline $\begin{array}{l}\text { Dimethoate } 4 \mathrm{EC} \text {, } \\
2.67 \mathrm{EC} \\
\text { (dimethoate) }\end{array}$ & $\begin{array}{l}\text { 4EC: } 0.5-1 \mathrm{pt} \\
2.67: 0.75-1.5 \\
\text { pt }\end{array}$ & 48 & $\begin{array}{l}0-2.67 \\
2-4 E\end{array}$ & $\begin{array}{l}\text { aphids, grasshoppers, } \\
\text { leafhoppers, leafminers }\end{array}$ & $1 \mathrm{~B}$ & Highly toxic to bees. \\
\hline $\begin{array}{l}\text { DiPel DF } \\
\text { (Bacillus thuringiensis } \\
\text { subspecies kurstaki) }\end{array}$ & $0.5-2.0 \mathrm{lb}$ & 4 & 0 & caterpillars & 11B2 & $\begin{array}{l}\text { Treat when larvae are young. } \\
\text { Good coverage is essential. OMRI- } \\
\text { listed². }^{2}\end{array}$ \\
\hline $\begin{array}{l}\text { *Di-Syston } 15 \text { G } \\
\text { (soil only) } \\
\text { (disulfoton) }\end{array}$ & $13.5-20.5 \mathrm{lb}$ & 48 & 75 , soil & $\begin{array}{l}\text { aphids, Colorado potato } \\
\text { beetle, flea beetles, leaf- } \\
\text { hoppers, wireworms }\end{array}$ & $1 \mathrm{~B}$ & $\begin{array}{l}\text { Do not make more than } 2 \text { soil } \\
\text { applications. See label for details. }\end{array}$ \\
\hline *8 EC (soil or foliar) & $2-3 \mathrm{pt}$ & & $\begin{array}{l}30, \\
\text { foliar } \\
75, \text { soil }\end{array}$ & $\begin{array}{l}\text { green peach aphid (east of } \\
\text { Rocky Mountains) }\end{array}$ & $1 B$ & No more than 3 foliar applications. \\
\hline $\begin{array}{l}\text { Endosulfan } 3 \text { EC } \\
\text { (endosulfan) }\end{array}$ & $0.66-1.33$ qts & 24 & 1 & $\begin{array}{l}\text { aphids, armyworms, } \\
\text { Colorado potato beetle, } \\
\text { false chinchbugs, flea } \\
\text { beetles, leafhoppers, plant } \\
\text { bugs, potato tuberworm, } \\
\text { stink bugs, three-lined } \\
\text { potato beetle, whiteflies }\end{array}$ & 2 & $\begin{array}{l}\text { No more than } 6 \text { applications per } \\
\text { year. }\end{array}$ \\
\hline $\begin{array}{l}\text { Entrust } \\
\text { (spinosad) }\end{array}$ & $1-30 z$ & 4 & 7 & $\begin{array}{l}\text { armyworms, Colorado } \\
\text { potato beetle, loopers, } \\
\text { thrips }\end{array}$ & 5 & $\begin{array}{l}\text { Do not apply to consecutive } \\
\text { generations of Colorado potato } \\
\text { beetle. Do not apply more than } 4 \\
\text { times/crop. }\end{array}$ \\
\hline $\begin{array}{l}\text { Extinguish } \\
((\mathrm{S}) \text {-methoprene) }\end{array}$ & $1.0-1.5 \mathrm{lb}$ & 4 & 0 & fire ants & $7 \mathrm{~A}$ & $\begin{array}{l}\text { Slow-acting IGR (insect growth } \\
\text { regulator). Best applied early } \\
\text { spring and fall where crop will be } \\
\text { grown. Colonies will be reduced } \\
\text { after three weeks and elimi- } \\
\text { nated after } 8 \text { to } 10 \text { weeks. May be } \\
\text { applied by ground equipment or } \\
\text { aerially. }\end{array}$ \\
\hline $\begin{array}{l}\text { Fulfill } \\
\text { (pymetrozine) }\end{array}$ & $2.75 \mathrm{oz}$ & 12 & 14 & $\begin{array}{l}\text { green peach aphid, potato } \\
\text { aphid }\end{array}$ & $9 \mathrm{~B}$ & Apply when aphids first appear. \\
\hline $\begin{array}{l}\text { *Furadan } 4 \mathrm{~F} \\
\text { (carbofuran) }\end{array}$ & $1-2 \mathrm{pts}$ & 48 & 14 & $\begin{array}{l}\text { Colorado potato beetle, } \\
\text { flea beetles, leafhoppers }\end{array}$ & $1 \mathrm{~A}$ & $\begin{array}{l}\text { See label for restrictions based on } \\
\text { soil type and water table. }\end{array}$ \\
\hline $\begin{array}{l}\text { Gaucho } \\
\text { (imidacloprid + man- } \\
\text { cozeb) }\end{array}$ & $\begin{array}{l}0.75 \mathrm{lb} / 100 \mathrm{lb} \\
\text { cut seed-pieces }\end{array}$ & 24 & $\begin{array}{l}\text { seed- } \\
\text { piece } \\
\text { treat- } \\
\text { ment }\end{array}$ & $\begin{array}{l}\text { aids in control of aphids, } \\
\text { Colorado potato beetle, } \\
\text { flea beetles, wireworms }\end{array}$ & $4 \mathrm{~A}$ & See label for restrictions. \\
\hline $\begin{array}{l}\text { Imidan } 70 \text { W } \\
\text { (phosmet) }\end{array}$ & $1.3 \mathrm{lb}$ & 24 & 7 & $\begin{array}{l}\text { Colorado potato beetle, } \\
\text { flea beetles, potato leaf- } \\
\text { hoppers }\end{array}$ & $1 \mathrm{~B}$ & $\begin{array}{l}\text { Use only on potatoes to be har- } \\
\text { vested by machine. }\end{array}$ \\
\hline $\begin{array}{l}\text { Javelin WG } \\
\text { (Bacillus thuringiensis } \\
\text { subspecies kurstaki) }\end{array}$ & $0.12-1.5 \mathrm{lb}$ & 4 & 0 & $\begin{array}{l}\text { most caterpillars, but not } \\
\text { Spodoptera species (army- } \\
\text { worms) }\end{array}$ & 11B2 & $\begin{array}{l}\text { Treat when larvae are young. } \\
\text { Thorough coverage is essential. } \\
\text { OMRI-listed². }^{2}\end{array}$ \\
\hline $\begin{array}{l}\text { Kryocide } \\
\text { (cryolite) }\end{array}$ & $10-12 \mathrm{lb}$ & 12 & 0 & Colorado potato beetle & $9 \mathrm{~A}$ & $\begin{array}{l}\text { Application to exposed tubers may } \\
\text { result in excess residues. }\end{array}$ \\
\hline $\begin{array}{l}\text { *Lannate LV; *SP } \\
\text { (methomyl) }\end{array}$ & $\begin{array}{l}\text { LV: } 1.5-3.0 \mathrm{pt} \\
\text { SP: } 0.5-1.0 \mathrm{lb}\end{array}$ & 48 & 6 & $\begin{array}{l}\text { aphids, beet armyworm, } \\
\text { fall armyworm, flea bee- } \\
\text { tles, leafhoppers, loopers, } \\
\text { potato tuberworm, varie- } \\
\text { gated cutworm }\end{array}$ & $1 \mathrm{~A}$ & \\
\hline
\end{tabular}


Table 9. Continued.

\begin{tabular}{|c|c|c|c|c|c|c|}
\hline $\begin{array}{l}\text { Trade Name } \\
\text { (Common Name) }\end{array}$ & $\begin{array}{l}\text { Rate } \\
\text { (product/acre) }\end{array}$ & $\begin{array}{l}\text { REI } \\
\text { (hours) }\end{array}$ & $\begin{array}{l}\text { Days to } \\
\text { Harvest }\end{array}$ & Insects & $\begin{array}{l}\text { MOA } \\
\text { Code }^{1}\end{array}$ & Notes \\
\hline $\begin{array}{l}\text { Lepinox WDG } \\
\text { (Bacillus thuringiensis } \\
\text { subspecies kurstaki) }\end{array}$ & $1.0-2.0 \mathrm{lb}$ & 12 & 0 & $\begin{array}{l}\text { for most caterpillars, } \\
\text { including beet armyworm } \\
\text { (see label) }\end{array}$ & 11B2 & $\begin{array}{l}\text { Treat when larvae are small. } \\
\text { Thorough coverage is essential. }\end{array}$ \\
\hline $\begin{array}{l}\text { Malathion 8F } \\
\text { (malathion) }\end{array}$ & $1-3 \mathrm{pt}$ & 12 & 0 & $\begin{array}{l}\text { aphids, false chinchbugs, } \\
\text { grasshoppers, mealybugs, } \\
\text { leafhoppers }\end{array}$ & $1 \mathrm{~B}$ & \\
\hline $\begin{array}{l}\text { *Mocap } 15 \text { G, *EC } \\
\text { (ethoprop) }\end{array}$ & See labels & 48 & $\begin{array}{l}\text { preplant } \\
\text { or at } \\
\text { planting }\end{array}$ & symphylans, wireworms & $1 \mathrm{~B}$ & \\
\hline $\begin{array}{l}\text { *Monitor } 4 \text { EC (meth- } \\
\text { amidophos) }\end{array}$ & $1.5-2 \mathrm{pts}$ & 48 & 14 & $\begin{array}{l}\text { aphids, armyworms, cab- } \\
\text { bage looper, Colorado } \\
\text { potato beetle, cutworms, } \\
\text { flea beetles, Lygus bug, } \\
\text { potato leafhopper, potato } \\
\text { tuberworm }\end{array}$ & $1 \mathrm{~B}$ & \\
\hline $\begin{array}{l}\text { M-Pede } \mathbf{4 9 \%} \text { EC } \\
\text { Soap, insecticidal }\end{array}$ & $1-2 \%$ V/N & 12 & 0 & $\begin{array}{l}\text { aphids, Colorado potato } \\
\text { beetle, leafhoppers, plant } \\
\text { bugs, thrips, whiteflies, } \\
\text { mites }\end{array}$ & -- & OMRI-listed². \\
\hline $\begin{array}{l}\text { Oberon 2SC } \\
\text { (spiromesifen) }\end{array}$ & $8-16 \mathrm{fl} \mathrm{oz}$ & 12 & 7 & $\begin{array}{l}\text { potato psyllid, twospotted } \\
\text { spider mite, whiteflies }\end{array}$ & 23 & $\begin{array}{l}\text { Maximum amount per crop: } 32.0 \\
\mathrm{fl} \text { oz/acre. Maximum applications: } \\
2 \text {. }\end{array}$ \\
\hline $\begin{array}{l}\text { *Penncap-M } \\
\text { (methyl parathion) }\end{array}$ & $2-6 \mathrm{pt}$ & $\begin{array}{l}4 \text { days } \\
\text { - See } \\
\text { label }\end{array}$ & 5 & $\begin{array}{l}\text { Colorado potato beetle, } \\
\text { cutworms, flea beetles, } \\
\text { grasshoppers, potato } \\
\text { leafhopper, tarnished plant } \\
\text { bug }\end{array}$ & $1 \mathrm{~B}$ & $\begin{array}{l}\text { Do not apply more than } 24 \text { pt per } \\
\text { acre per year. }\end{array}$ \\
\hline $\begin{array}{l}\text { Platinum } \\
\text { (thiamethoxam) }\end{array}$ & $5-8 \mathrm{fl} \mathrm{oz}$ & 12 & $\begin{array}{l}\text { applied } \\
\text { at plant- } \\
\text { ing or } \\
\text { at plant } \\
\text { emer- } \\
\text { gence }\end{array}$ & $\begin{array}{l}\text { aphids, Colorado potato } \\
\text { beetles, flea beetles, } \\
\text { potato leafhoppers }\end{array}$ & $4 \mathrm{~A}$ & $\begin{array}{l}\text { For most crops that are not on the } \\
\text { label, a 120-day plant-back inter- } \\
\text { val must be observed. To manage } \\
\text { resistance, avoid using Actara } \\
\text { or Provado in conjunction with } \\
\text { Platinum. }\end{array}$ \\
\hline $\begin{array}{l}\text { *Pounce } 3.2 \text { EC (per- } \\
\text { methrin) }\end{array}$ & $4-80 z$ & 12 & 14 & $\begin{array}{l}\text { aphids, aster leafhopper, } \\
\text { beet armyworm, cabbage } \\
\text { looper, Colorado potato } \\
\text { beetle, cutworms, flea } \\
\text { beetles, leafhoppers, pota- } \\
\text { to tuberworm, tarnished } \\
\text { plant bug }\end{array}$ & 3 & \\
\hline $\begin{array}{l}\text { Provado } 1.6 \text { F (imida- } \\
\text { cloprid) }\end{array}$ & $3.80 \mathrm{z}$ & 12 & 7 & $\begin{array}{l}\text { aphids, Colorado potato } \\
\text { beetle, flea beetles, leaf- } \\
\text { hoppers }\end{array}$ & $4 \mathrm{~A}$ & $\begin{array}{l}\text { Do not use if other } 4 \mathrm{~A} \text { insecticides } \\
\text { have been used at planting. }\end{array}$ \\
\hline $\begin{array}{l}\text { Pyrellin EC } \\
\text { (pyrethrin + rotenone) }\end{array}$ & $1-2 \mathrm{pt}$ & 12 & $\begin{array}{l}12 \\
\text { hours }\end{array}$ & $\begin{array}{l}\text { aphids, Colorado potato } \\
\text { beetle, cucumber beetles, } \\
\text { flea beetles, leafhoppers, } \\
\text { leafminers, loopers, Lygus } \\
\text { bugs, mites, plant bugs, } \\
\text { stink bugs, thrips, veg- } \\
\text { etable weevil, whiteflies }\end{array}$ & 3,21 & \\
\hline $\begin{array}{l}\text { Rimon 0.83EC } \\
\text { (novaluron) }\end{array}$ & $9-12 \mathrm{fl} \mathrm{oz}$ & 12 & 14 & $\begin{array}{l}\text { armyworms, Colorado } \\
\text { potato beetle, loopers, } \\
\text { other foliage feeding cater- } \\
\text { pillars, potato tubermoth, } \\
\text { whiteflies }\end{array}$ & 15 & $\begin{array}{l}\text { Do not apply more than } 24 \text { oz } \\
\text { per acre per season. Limited to } 2 \\
\text { applications. }\end{array}$ \\
\hline
\end{tabular}


Table 9. Continued.

\begin{tabular}{|c|c|c|c|c|c|c|}
\hline $\begin{array}{l}\text { Trade Name } \\
\text { (Common Name) }\end{array}$ & $\begin{array}{l}\text { Rate } \\
\text { (product/acre) }\end{array}$ & $\begin{array}{l}\text { REI } \\
\text { (hours) }\end{array}$ & $\begin{array}{l}\text { Days to } \\
\text { Harvest }\end{array}$ & Insects & $\begin{array}{l}\text { MOA } \\
\text { Code }^{1}\end{array}$ & Notes \\
\hline $\begin{array}{l}\text { Sevin XLR, } 4 \text { F; } 80 \text { S } \\
\text { (carbaryl) }\end{array}$ & $\begin{array}{l}\text { XLR, 4F: } 0.5- \\
2.0 \text { qt } \\
\text { 80S: } 0.63-2.5 \mathrm{lb}\end{array}$ & 12 & 7 & $\begin{array}{l}\text { Colorado potato beetle, } \\
\text { corn earworm, cutworms, } \\
\text { fall armyworm, flea bee- } \\
\text { tles, hornworms, leafhop- } \\
\text { pers, stink bugs, tarnished } \\
\text { plant bug, tomato fruit- } \\
\text { worm, tomato hornworm }\end{array}$ & $1 \mathrm{~A}$ & $\begin{array}{l}\text { Do not apply more than a total of } \\
6 \text { qt or } 7.5 \mathrm{lb} \text {. }\end{array}$ \\
\hline $\begin{array}{l}\text { SpinTor } 2 \text { SC } \\
\text { (spinosad) }\end{array}$ & $3-6 \mathrm{fl} \mathrm{oz}$ & 4 & 7 & $\begin{array}{l}\text { armyworms, Colorado } \\
\text { potato beetle, leafminers } \\
\text { (Liriomyza spp.), loopers, } \\
\text { thrips }\end{array}$ & 5 & $\begin{array}{l}\text { Do not apply to consecutive gen- } \\
\text { erations of Colorado potato beetle, } \\
\text { or make more than } 2 \text { applications } \\
\text { per single generation. }\end{array}$ \\
\hline $\begin{array}{l}\text { Sun Spray } 98.8 \% \text {, } \\
\text { JMS Stylet-0il, others } \\
\text { (oil, insecticidal) }\end{array}$ & $\begin{array}{l}3-6 \mathrm{qt} / 100 \mathrm{gal} \\
(\mathrm{JMS})\end{array}$ & 4 & 0 & $\begin{array}{l}\text { leafhoppers, leafminers, } \\
\text { thrips, whiteflies, mites }\end{array}$ & -- & $\begin{array}{l}\text { See label for tank mix cautions. } \\
\text { Organic Stylet-Oil is OMRI-listed }{ }^{2} \text {. }\end{array}$ \\
\hline $\begin{array}{l}{ }^{*} \text { Telone C-35 (dichlo- } \\
\text { ropropene + chloro- } \\
\text { picrin) } \\
{ }^{*} \text { Telone II } \\
\text { (dichloropropene) }\end{array}$ & See label & $\begin{array}{l}5 \text { days } \\
\text { - See } \\
\text { label }\end{array}$ & preplant & symphylans, wireworms & -- & $\begin{array}{l}\text { See supplemental label for addi- } \\
\text { tional use restrictions for certain } \\
\text { counties. }\end{array}$ \\
\hline $\begin{array}{l}\text { *Temik } 15 \text { G } \\
\text { (aldicarb) }\end{array}$ & $14-20 \mathrm{lb}$ & 48 & $\begin{array}{l}\text { At plant- } \\
\text { ing }\end{array}$ & $\begin{array}{l}\text { aphids, Colorado potato } \\
\text { beetle, flea beetles, leaf- } \\
\text { hoppers }\end{array}$ & $1 \mathrm{~A}$ & $\begin{array}{l}\text { Do not apply after planting. See } \\
\text { label for other restrictions. }\end{array}$ \\
\hline $\begin{array}{l}\text { *Thimet } 20 \text { G } \\
\text { (phorate) }\end{array}$ & $\begin{array}{l}\text { See label - var- } \\
\text { ies with soil } \\
\text { type and time of } \\
\text { application. }\end{array}$ & 48 & 90 & $\begin{array}{l}\text { aphids, Colorado potato } \\
\text { beetle, flea beetles (lar- } \\
\text { vae), leafhoppers, leafmin- } \\
\text { ers, wireworms }\end{array}$ & $1 \mathrm{~B}$ & One application per season. \\
\hline $\begin{array}{l}\text { Trilogy } \\
\text { (extract of neem oil) }\end{array}$ & $0.5-2.0 \% \mathrm{~V} / \mathrm{V}$ & 4 & 0 & $\begin{array}{l}\text { aphids, mites, suppression } \\
\text { of thrips and whiteflies }\end{array}$ & 26 & $\begin{array}{l}\text { Apply morning or evening to } \\
\text { reduce potential for leaf burn. } \\
\text { Toxic to bees exposed to direct } \\
\text { treatment. } \\
\text { OMRI-listed². }\end{array}$ \\
\hline $\begin{array}{l}\text { Venom } \\
\text { (dinotefuran) }\end{array}$ & $\begin{array}{l}\text { foliar: } 1-1.5 \mathrm{oz} \\
\text { soil: } 6.5-7.5 \mathrm{oz}\end{array}$ & 12 & $\begin{array}{l}\text { foliar } \\
-7 \\
\text { soil - at } \\
\text { planting }\end{array}$ & $\begin{array}{l}\text { Colorado potato beetle, } \\
\text { flea beetle, green peach } \\
\text { aphid, potato leafhopper, } \\
\text { psyllid }\end{array}$ & $4 \mathrm{~A}$ & $\begin{array}{l}\text { Soil application one time either } \\
\text { at preplant, preemergence, or at } \\
\text { ground crack. }\end{array}$ \\
\hline $\begin{array}{l}\text { *Vydate L } \\
\text { (oxamyl) }\end{array}$ & foliar: 2-4 pt & 48 & 7 & $\begin{array}{l}\text { aphids, Colorado potato } \\
\text { beetle, flea beetles, leaf- } \\
\text { hoppers, tarnished plant } \\
\text { bug }\end{array}$ & $1 \mathrm{~A}$ & $\begin{array}{l}\text { No more than } 6 \text { foliar applica- } \\
\text { tions per crop. }\end{array}$ \\
\hline $\begin{array}{l}\text { Xentari DF } \\
\text { (Bacillus thuringiensis } \\
\text { subspecies aizawai) }\end{array}$ & $0.5-2.0 \mathrm{lb}$ & 4 & 0 & caterpillars & $11 \mathrm{~B} 1$ & $\begin{array}{l}\text { Treat when larvae are young. } \\
\text { Thorough coverage is essential. } \\
\text { May be used in the greenhouse. } \\
\text { Can be used in organic produc- } \\
\text { tion. }\end{array}$ \\
\hline
\end{tabular}

The pesticide information presented in this table was current with federal and state regulations at the time of revision. The user is responsible for determining the intended use is consistent with the label of the product being used. Use pesticides safely. Read and follow label instructions. 
Table 9. Continued.

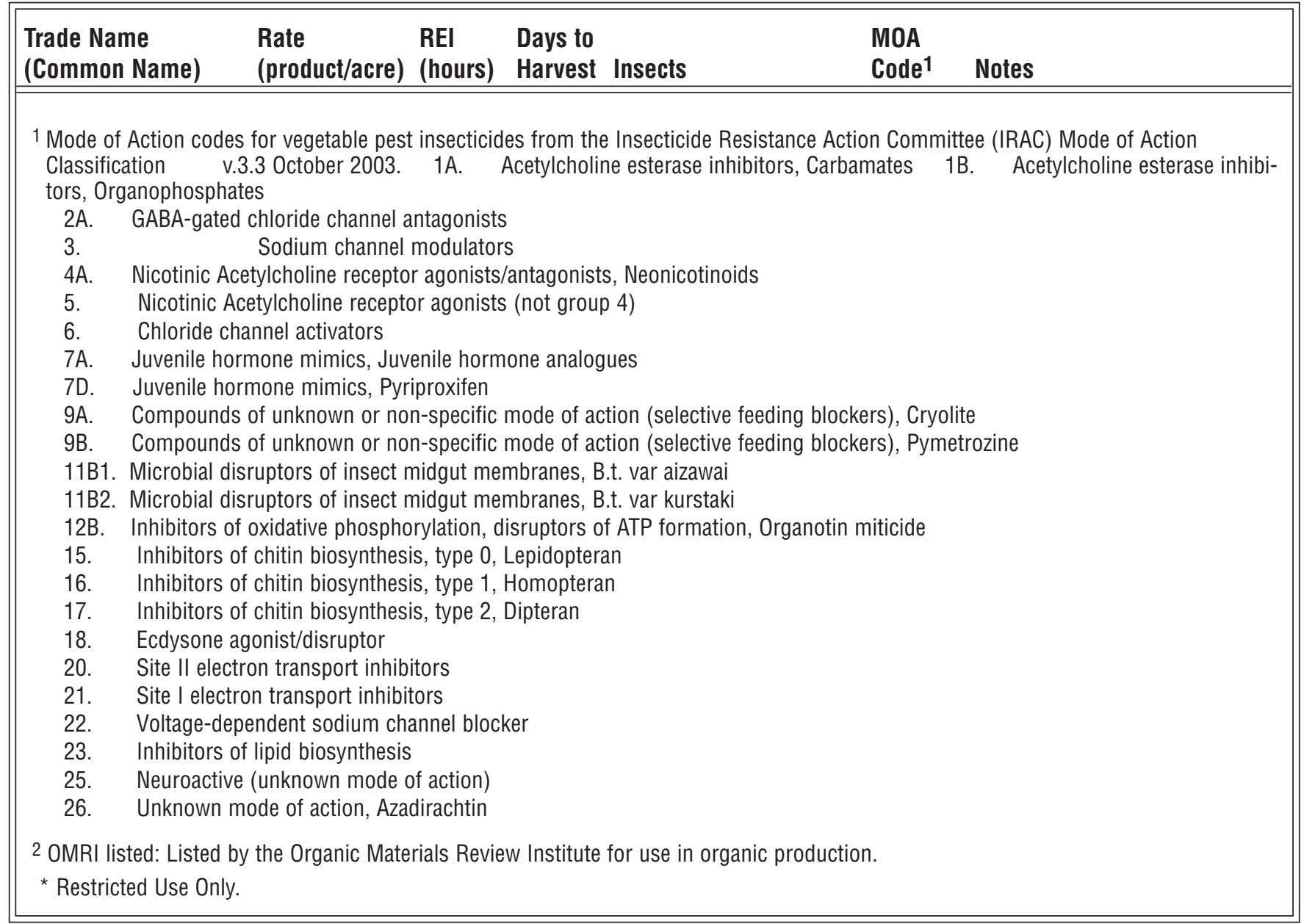

Table 10. Breakeven production costs of chip potatoes at various yield levels in the Hastings area, 2004-2005.

\begin{tabular}{|lcccccc|}
\hline & & \multicolumn{5}{c|}{ Yield (cwt/acre) } \\
\cline { 3 - 6 } & Cost per acre & $\mathbf{1 7 5}$ & $\mathbf{2 0 0}$ & $\mathbf{2 2 5}$ & $\mathbf{2 5 0}$ & $\mathbf{2 7 5}$ \\
\hline \hline Variable Costs & $\$ 1,541.19$ & $\$ 8.81$ & $\$ 7.71$ & $\$ 6.85$ & $\$ 6.16$ & $\$ 5.60$ \\
Fixed Costs & $\$ 593.38$ & $\$ 3.39$ & $\$ 2.97$ & $\$ 2.64$ & $\$ 2.37$ & $\$ 2.16$ \\
Harvest Cost/unit & & $\$ 1.00$ & $\$ 1.00$ & $\$ 1.00$ & $\$ 1.00$ & $\$ 1.00$ \\
Total Cost/unit & & $\$ 13.20$ & $\$ 11.67$ & $\$ 10.49$ & $\$ 9.54$ & $\$ 8.76$ \\
\hline
\end{tabular}

